\title{
A ARTE NEOLIBERAL DE GOVERNAR E A TEORIA DO CAPITAL HUMANO: PERSPECTIVAS CRÍTICAS EM EDUCAÇÃO E TRABALHO
}

Diego dos Santos Reis ${ }^{\mathbf{i}}$

Resumo: Este artigo objetiva discutir alguns aspectos da genealogia da governamentalidade neoliberal, tal como realizada por Michel Foucault nos últimos cursos da década de 70, no Collège de France. Trata-se, principalmente, de analisar os desdobramentos dessa genealogia no que concerne à formação do sujeito empreendedor, polivalente, proativo e flexível, concebido por essa arte de governo neoliberal como "empresários de si mesmos". Objetiva-se, assim, problematizar as implicações e os efeitos da teoria do capital humano no campo da educação e do trabalho, bem como da progressiva governamentalização do Estado e das condutas individuais, regulados pelo mercado.

Palavras-chave: Governamentalidade neoliberal; Teoria do capital humano; Sujeito empreendedor.

Abstract: This paper aims to discuss about some aspects of the genealogy of neoliberal governmentality, as carried out by Michel Foucault in the last courses of the 70s, at the Collège de France. The main goal is to analyze the consequences of this genealogy with regard to the education of the entrepreneurial, versatile, proactive and flexible subject, conceived by this art of neoliberal government as "entrepreneurs of themselves". Thus, the purpose is to question the implications and effects of the theory of human capital in educational studies and work, as well as the progressive governmentalization of the State and individual conduct, regulated by the market.

Keywords: Neoliberal governmentality; Human capital theory; Entrepreneurial subject.

\section{Introdução}

Em algumas passagens seminais do curso Nascimento da Biopolítica, Michel Foucault (2008) define a governamentalidade neoliberal como um modo particular de produção de subjetividade e de um tipo de sujeito que seria um empresário de si mesmo. Nessa perspectiva, os sujeitos seriam, sobretudo, empreendedores, cuja tarefa primordial consistiria em investir permanentemente em seu capital humano, com vistas a maximizá-lo.

A novidade dessa razão política, porém, não está instanciada somente na crítica contundente que endereça ao Estado de bem-estar social e às políticas assistencialistas, na reivindicação da privatização do social e na defesa das políticas de austeridade que pautam seus programas de ajustes estruturais. A razão neoliberal, como propõe Foucault, estende-se aos âmbitos mais recônditos da existência e dos fenômenos sociais, compreendendo-os como condutas econômicas racionalizadas por cálculos de interesse.

Interessa-nos, aqui, pensar de que modo essa racionalidade de governo impacta no campo educacional, mobilizando não só um vocabulário próprio do mundo empresarial, mas sentidos e valores 
econômicos transpostos para o domínio da formação humana, do trabalho e da educação. Isto porque a governamentalidade neoliberal incluiu, no cerne de suas concepções econômico-políticas, processos de subjetivação voltados para sujeitos convertidos em máquinas-competência, segundo uma cultura do empreendedorismo:

[...] trata-se de desdobrar o modelo econômico, o modelo oferta e procura, o modelo investimento-custo-lucro, para dele fazer um modelo das relações sociais, um modelo da existência, uma forma de relação do indivíduo consigo mesmo, com o tempo, com seu círculo, com o futuro, com o grupo, com a família (FOUCAULT, 2008, p. 332).

A emergência da razão neoliberal marca, portanto, um deslocamento notório nas práticas de governo. O par mercado-homo oeconomicus substitui, assim, no modelo proposto por essa racionalidade econômica, o paradigma soberania-sujeito de direito, binômio que por longo tempo ofereceu o fundamento da teoria política clássica. Doravante, o tribunal econômico permanente que se torna o mercado passa a ser o regulador social geral das políticas governamentais, pensadas e praticadas "segundo critérios essencialmente técnicos” (FONSECA, 2013, p. 160).

Por conseguinte, as transformações contemporâneas na vida individual e na vida social dos sujeitos, orientadas pelo mercado como instância privilegiada de formatação da verdade, colocam sob o domínio econômico todas as esferas da existência. Essas transformações dizem respeito, particularmente, às políticas de subjetivação que acompanham as práticas econômicas e aos modos de sociabilidade ligados a elas, bem como ao seu repertório de representações. Como destaca Ramos do Ó:

A questão em causa não é a da coerção e dos constrangimentos exercidos sobre a massa dos governados. O poder liga-se antes aos modos como, numa dinâmica onde a autonomia e a liberdade estão cada vez mais presentes, se produzem cidadãos. Estes não são destinatários, mas intervenientes nos jogos e nas operações de poder (RAMOS DO Ó, 2005, p. 17).

Do cidadão ao homo oeconomicus, alçado a personagem principal para o qual as regras do jogo devem ser reguladas, um deslocamento importante merece ser remarcado. Se, de um lado, as relações de mercado ganham primeiro plano nas análises, como modo de decifração dos fenômenos sociais, de outro, conduzir as condutas desses agentes econômicos e intervir sobre suas ações futuras, sem lhes retirar, todavia, a superfície de ação e deliberação prometidas, demandará formas refinadas e flexíveis de produção de estímulos, com vistas a regrar os comportamentos dos indivíduos segundo os princípios da competitividade e da dinâmica concorrencial das sociedades empresariais. Na medida em que será preciso governar para o mercado e que o governo diz respeito às técnicas e tecnologias de condução de condutas, será preciso produzir a conduta desejável aos indivíduos, no interior dessa arte de governo neoliberal: 
Trata-se aí da descoberta de que a determinação do padrão comportamental por parte dos indivíduos e da população já não depende mais apenas da atuação governamental administrativa por parte do Estado, pois o próprio mercado econômico de concorrência também pode perfeitamente se encarregar disso, atuando de maneira ágil, descentralizada e bastante eficaz como instância de produção de subjetividades (DUARTE, 2010, p. 263).

A reconfiguração das subjetividades nos moldes de um ethos empresarial, isto é, de uma cultura do empreendedorismo e das competências, será expressa em um modo de ser segundo o qual o "humano" se torna "um conjunto de capacidades, destrezas e aptidões próprias dos homens, adquire valor de mercado e se apresenta como forma de capital - entendido como uma soma de valores de troca que serve de base real a uma empresa capitalista” (LÓPES-RUIZ, 2007, p. 18). O empreendedorismo e a responsabilidade individual como mecanismos de ancoragem da administração dos processos de subjetivação fixam, igualmente, o sujeito como o lugar de agenciamentos variáveis, identidades flexíveis e produto de um investimento de capital que deve ser capaz de jogar com os riscos característicos dos processos de produção de si mesmos.

Há o redimensionamento, ademais, das relações humanas e dos novos controles das subjetividades dos governados que, por outro lado, geram novas dinâmicas de liberdade-dependência ${ }^{\mathrm{ii}}$, decorrentes dos processos de governo econômico das populações pela via do mercado. Assim, a forma-empresa que se dissemina como potência enformadora da sociedade torna-se o modelo de organização para todo o campo social, com suas técnicas de governo multifacetadas. E, evidentemente, a escola não passará incólume a esse projeto gerencial, que prevê:

[...] uma mudança substantiva nas práticas pedagógicas, tornando-as mais eficientes; reestruturar o sistema para flexibilizar a oferta educacional; promover uma mudança cultural, não menos profunda, nas estratégias de gestão (agora guiadas pelos novos conceitos de qualidade total); reformular o perfil dos professores, requalificando-os; implementar uma ampla reforma curricular, etc. (GENTILI, 1996, p. 18. Grifos do autor).

Os sujeitos econômicos, nesse cenário, parecem responder às demandas materiais e simbólicas da sociedade para a qual se voltam, segundo denominadores comuns de um mercado transnacionalizado e "onisciente", que regula seus comportamentos. Um dos aspectos mais significativos desse novo ethos empresarial, entretanto, talvez seja o trabalho que o sujeito é instado a desempenhar sobre si mesmo e seu "destino", com vistas a uma boa performance e à autovalorização que se transmuta em esforço, vigor, sucesso, eficiência.

\section{Self-made man}


Se a governamentalidade biopolítica volta-se, sobretudo, às regulações que envolvem as populações, a racionalidade de governo neoliberal, nos marcos da forma-empresa, tem por alvo o trabalho do indivíduo sobre si mesmo, intencionando a formação de um determinado tipo de sujeito: competente, inovador, proativo, polivalente.

Os modos por meio dos quais os indivíduos constituem-se a si mesmos segundo o modelo "verdadeiro" do empreendedor são levados a cabo por práticas e processos de subjetivação, pelos quais o sujeito é modificado a partir das possibilidades de lucro que são entrevistas. Nesse sentido, "a 'responsabilidade' dos indivíduos constitui uma forma de moralidade de mercado, entendida como a maximização da economia por meio da deliberação racional autônoma de custos e benefícios, seguida por práticas livremente escolhidas" (HAMANN, 2012, p. 110). O homo oeconomicus neoliberal, deste modo, é compreendido como um "átomo" de interesse próprio, livre e autônomo, totalmente responsável pelos cálculos de escolha racional e de custo-benefício traçados por ele. Consequentemente, esses "neosujeitos" são individuados segundo as diretrizes de autoinvestimento e de especialização permanente, em cujo cerne está o conjunto das competências verificáveis - e, por conseguinte, avaliáveis - a serem adquiridas por eles.

Daí, formar sujeitos adaptáveis aos diversos contextos e situações torna-se o móvel dessas práticas de subjetivação. Afinal, o empreendedor - ou business man - será o sujeito que possui um rol de virtudes traçadas pelo discurso da boa administração (management) e que são a chave das performances eficazes dos sujeitos sempre motivados: flexibilidade, criatividade, adaptabilidade, competência.

O ideal do empreendedor vitoriano, do self-made man deste mundo novo, é aquele de um homem de caráter, diferente do aristocrata inativo e decadente. Suas virtudes são o controle de si, a energia, a diligência, a frugalidade, a parcimônia [l'esprit d'économie], a prudência, a paciência, a perseverança, a honestidade, a integridade, a temperança, a sobriedade, e o senso do dever (AUDARD, 2009, p. 168). iii

Não estranha que o self-made man tipifique o sujeito ambicionado pelo modelo neoliberal, cuja capacidade de inovação e cujo espírito pioneiro o tornam verdadeiro agente do desenvolvimento econômico. Essas virtudes características da nova classe empreendedora figuram no núcleo da teologia política da prosperidade que vigora nas sociedades neoliberais - e que aponta a um "aqui e agora" demasiado humanos, cujas recompensas são o sucesso financeiro e a realização individual. Nessa lógica, o indivíduo capaz de investir e criar a si mesmo torna-se o responsável pelo seu destino, por seu próprio mérito e self-reliance, como sublinha o discurso da meritocracia neoliberal.

A nova gramática dos valores morais, então, inclui em seu léxico aquelas que seriam as virtudes primordiais do sujeito empreendedor: competente e competitivo; motivado e proativo; visionário e interessado; flexível e polivalente. Vemos todo um conjunto de predicados e adjetivos que são mobilizados, 
tendo em vista as subjetividades requeridas para o "admirável mundo novo" do neoliberalismo. Note-se que essas mutações subjetivas são embasadas por uma espécie de ética da assertividade, por meio da qual o sucesso é internalizado como responsabilidade individual dos sujeitos; e o fracasso, como culpa. Nesse horizonte, todos são igualmente responsáveis pelo seu sucesso ou fracasso, pois é o mercado que realiza a paridade entre os cidadãos, marcado - supostamente - pela igualdade de oportunidades.

Interessante destacar, todavia, a crítica traçada por Brown, ao marcar o "sujeito não marcado do neoliberalismo":

O capital humano, no linguajar neoliberal, não possui gênero, sexualidade, raça ou qualquer outra posição subjetiva. Porém, é claro, o neoliberalismo se intersecciona com poderes existentes de estratificação, marginalização e estigmatização, reconfigurando e reafirmando esses poderes. A necessidade de marcação desse sujeito "sem rosto", na contramão do que é defendido pelos teóricos neoliberais, é essencial para se ressaltar as disparidades estruturais e os efeitos diferenciados que atingem mais determinados segmentos do que outros. E que inserseccionam vulnerabilidades e violências no discurso e na prática da "cidadania sacrificial" vigentes na racionalidade neoliberal (BROWN, 2018, p. 54).

Ao forjar toda uma palheta de categorizações que escande o corpo social, incita-se à produção do capital humano valorado e à hierarquização de humanidades que diferencia os vencedores (winners) e os fracassados/perdedores (losers), desconsiderando desigualdades estruturais que atingem de modo diferenciado pessoas vulnerabilizadas. Aqueles que não assimilam as competências necessárias às novas dinâmicas econômicas tornam-se supranumerários, além de serem vistos como "peso econômico" para a sociedade e para as instâncias governativas - logo, sacrificáveis.

Investir, inovar, empreender e arriscar, nesse contexto, tornam-se as palavras de ordem e de ordenamento dos âmbitos social e individual. Os competidores não são vistos como ligados por laços de cidadania ou por vínculos de solidariedade, mas pelo individualismo moral, que fundamenta o "despotismo do indivíduo", segundo o qual cada um é soberano de si e do seu por vir (AUDARD, 2009, p. 40). Como já notava Deleuze (2013, p. 225), em seu Post-scriptum sobre as sociedades de controle, “[...] a empresa introduz o tempo todo uma rivalidade inexpiável como sã emulação, excelente motivação que contrapõe os indivíduos entre si e atravessa cada um, dividindo-o em si mesmo".

Cabe ressaltar, de outro lado, que a governamentalidade neoliberal não substituiu, como uma linha contínua de sucessivas evoluções, as sociedades de soberania, disciplinar ou biopolítica. Muito pelo contrário. Em que pesem as linhas de força dominantes da governamentalidade neoliberal contemporânea, é no bojo dessa racionalidade que não cessamos de constatar a proliferação de tecnologias de controle de instituições que intensificam e sofisticam os dispositivos de "governo dos vivos":

Vocês não têm mecanismos de segurança que tomam o lugar dos mecanismos disciplinares, os quais teriam tomado o lugar dos mecanismos jurídico-legais. $\mathrm{Na}$ 
verdade, vocês têm uma série de edifícios complexos nos quais o que vai mudar, claro, são as próprias técnicas que vão se aperfeiçoar ou, em todo caso, se complicar, mas o que vai mudar, principalmente, é a dominante ou, mais exatamente, o sistema de correlação entre os mecanismos jurídico-legais, os mecanismos disciplinares e os mecanismos de segurança (FOUCAULT, 2004, p. 10).

Por essa via, a segurança torna-se um dos principais aspectos normativos na constituição da vida política nos regimes democráticos da atualidade. E a experiência cotidiana nos mostra que essa preocupação tem um lastro real, na medida em que, de modo inédito, assistimos a um alargamento crescente do uso das técnicas e tecnologias de segurança, cada vez mais incisivas e insidiosas, que escrutinam e perscrutam a vida dos governados, constrangendo-os a medições e aferições biométricas, algorítmicas e nanotecnológicas.

A era neoliberal intensificou e estendeu o gerenciamento das populações, apoiando-se em práticas concorrenciais e de autoinvestimento produtivo. Se, por um lado, a arte de governo neoliberal produz as liberdades de que necessita, apoiando-se nelas, por outro, consome e anula permanentemente essas mesmas liberdades. Não é de se estranhar, portanto, que essa dinâmica contínua de produção-destruição necessite de uma série de coerções, ameaças e estabelecimento de limites a partir dos quais se organizam e se dinamizam as operações que caracterizam essa arte de governo.

Ora, essas dinâmicas de promoção da liberdade e de penalizações acentuadas parecem lidar com algo paradoxal, em alguma medida. Se recordarmos, todavia, que desde o curso Segurança, Território, População, de 1977-1978, Foucault já alertava para o lugar privilegiado dos dispositivos de segurança como instrumentos técnico-operativos essenciais da governamentalidade política, não será fortuito afirmar que:

[...] a todos esses imperativos - zelar para que a mecânica dos interesses não provoque perigo nem para os indivíduos nem para a coletividade - devem corresponder estratégias de segurança que são, de certo modo, o inverso e a própria condição do liberalismo. A liberdade e a segurança, o jogo liberdade e segurança é isso que está no âmago dessa nova razão governamental cujas características gerais eu lhes vinha apontando. Liberdade e segurança - é isso que vai animar internamente, de certo modo, os problemas do que chamarei de economia do poder própria do liberalismo (FOUCAULT, 2008, p. 89).

Desse modo, haveria um nexo inextrincável entre liberdade e segurança na economia política dos (neo)liberalismos, que torna o Estado altamente intervencionista do ponto de vista político-penal. A economia das penas e dos castigos que acompanha a governamentalidade neoliberal evidencia a expansão das funções simbólicas e instrumentais do aparelho penal, que redireciona o Estado social ao Estado penal, com sua burocracia beligerante e sua lógica punitiva (WACQUANT, 2014). A penalização insidiosa que acossa os governados, como contenção punitiva, atinge, todavia, de modos diferenciados os sujeitos. Há os 
capitais humanos mais "valorados" e, também, os "refugos do mercado", pois não resta dúvida de que critérios étnico-raciais, de classe, de gênero e sexualidades são marcadores biopolíticos de diferenciação que mobilizam diferentes estratégias das políticas de segurança pública (STANCHI; REIS, 2018). Com relação a isso, Hamann (2012, p. 112) atenta para o fato de que "a abordagem neoliberal para lidar com a pobreza, o desemprego e a falta de moradia crescentes não é simplesmente ignorá-los, mas impor julgamentos punitivos por meio de efeitos moralizantes de sua racionalidade política”.

Por outro lado, salienta Foucault (2008, p. 91), "não há liberalismo sem cultura do perigo". Ser uma unidade-empreendedora de si exige viver inteiramente no risco. Os riscos de mercado demandam, por sua vez, recurso às técnicas e tecnologias securitárias e seguros privados diversos. Isso porque, "em seu discurso, o risco é dado como uma dimensão ontológica" (DARDOT; LAVAL, 2009, p. 428), isto é, correr riscos é inerente a uma vida de investimentos, empreendimentos e atividade:

Isso, claro, acarreta certo número de consequências. Podemos dizer que, afinal de contas, o lema do liberalismo é "viver perigosamente". "Viver perigosamente" significa que os indivíduos são postos perpetuamente em situação de perigo, ou antes, são condicionados a experimentar sua situação, sua vida, seu presente, seu futuro como portadores de perigo. É essa espécie de estímulo do perigo que vai ser, a meu ver, uma das principais implicações do liberalismoiv (FOUCAULT, 2008, p. 90).

Perigos perpetuamente atualizados e colocados constantemente em circulação. É preciso sublinhar, porém, que a produção e a gestão social e política dos riscos, na racionalidade neoliberal, é individualizada. O risco, por seu turno, não só circula pelos interiores, mas é englobado pelas esferas de mercado, tornandose comercializável - e rentável. E não há grande espanto em constatar que, se por um lado, produz-se o sujeito do risco, por outro, é igualmente produzido o sujeito da segurança privada. Todos tornam-se responsáveis individuais pelo seu futuro, às expensas do comum e da dimensão coletiva da existência, e transformam-se em sujeitos autorreferentes. Ou, ainda, no que Ulrich Beck (2013, p. 133 et seq.) chama, em A sociedade do risco, de "agentes de sua própria subsistência, mediada pelo mercado".

A ideia de uma privatização dos mecanismos de seguro, em todo caso a ideia de que cabe ao indivíduo, pelo conjunto das reservas de que ele vai poder dispor, seja a título simplesmente individual, seja por intermédio das sociedades de ajuda mútua etc., [proteger-se dos riscos] esse objetivo é, apesar de tudo, o que vocês vêem em ação nas políticas neoliberais [...]. É essa a tendência: a política social privatizada (FOUCAULT, 2008, p. 198-199).

A governamentalidade neoliberal apresenta-se, como ressalta Foucault, nos contornos de uma arte governamental securitária. Tecnologia permanente de governo que, baseada no discurso das "razões de segurança”, visa governar os efeitos advindos das crises que irrompem no seio da racionalidade neoliberal. 
Crises, aliás, que das catástrofes ambientais e pandemias aos terrorismos transnacionais reforçam o discurso da centralidade dos mecanismos de segurança, em meio à suspensão da "ordem normal" do fluxo das coisas (REIS, 2020b).

A securitização da vida compreende estratégias de conjunto polimorfas, que se destinam a gerir os riscos da vida cotidiana e que tendem a "conceder a cada um uma espécie de espaço econômico dentro do qual podem assumir e enfrentar os riscos" (FOUCAULT, 2008, p. 198). Sem dúvida, nas análises de Foucault, isso desempenha um papel fulcral para a progressiva "governamentalização" do Estado, com seus programas de gerenciamento dos riscos sociais. Sob o signo da segurança, é necessário:

[...] proteger o interesse coletivo contra os interesses individuais. Inversamente, a mesma coisa: será necessário proteger os interesses individuais contra tudo o que puder se revelar, em relação a eles, como um abuso vindo do interesse coletivo. É necessário também que a liberdade dos processos econômicos não seja um perigo, um perigo para as empresas, um perigo para os trabalhadores. A liberdade dos trabalhadores não pode se tornar um perigo para a empresa e para a produção. Os acidentes individuais, tudo o que pode acontecer na vida de alguém, seja a doença, seja esta coisa que chega de todo mundo, que é a velhice, não podem constituir um perigo nem para os indivíduos nem para a sociedade (FOUCAULT, 2008, p. 89).

Na dobra biopolítica e governamental do Estado, a razão securitária assenta-se na coexistência de lógicas heterogêneas: responsabilidade individual e governo das populações. Liberdade e insegurança são polos alternadamente enfatizados que, em nome da imprevisibilidade do perigo, "condiciona a indeterminabilidade dos critérios adotados pelos dispositivos securitários" (BAZZICALUPO, 2014, p. 83). Entre Estado e população, a relação é mediada, portanto, por um pacto de segurança, que significa, não raro, um princípio de exceção permanente que perpassa as democracias neoliberais contemporâneas. Nesse pacto, entretanto, seguridade e insegurança são as duas faces de um mesmo processo: a produção de liberdade é análoga à multiplicação dos dispositivos de segurança.

\section{Teoria do Capital Humano}

É nessa perspectiva que Foucault analisará dois tipos de programação do neoliberalismo norteamericano, propostos por pensadores da Escola de Chicago: a teoria do capital humano e o programa de estudo da criminalidade e da delinquência (REIS, 2020). Esses dois elementos ganham relevância e acuidade por representarem dois processos:

[...] de incursão da análise econômica em um campo até então inexplorado e, segundo, a partir daí e a partir dessa incursão, a possibilidade de reinterpretar em termos econômicos e em termos estritamente econômicos todo um campo que, até 
então, podia ser considerado, e era de fato considerado, não-econômico (FOUCAULT, 2008, p. 302).

A incursão da análise econômica em níveis inexplorados até então fundamenta a crítica endereçada a certo esquecimento nos trabalhos dos liberais clássicos, mormente de Adam Smith e de Ricardo. Se a produção de bens, na economia política clássica, estava subordinada à terra, ao capital e ao trabalho que, em sua triangulação, são os fatores-chave da análise econômica, o fator trabalho, reivindicam os neoliberais, não mereceu atenção suficiente por parte desses teóricos, sempre reduzido ao fator tempo. Como resultado do diagnóstico desse lapso, os neoliberais tentam reintroduzir o trabalho no campo da análise econômica, não a partir de seus mecanismos de produção, reprodução e troca, mas como "conduta econômica praticada, construída, racionalizada, calculada por aquele que trabalha” (LAZZARATO, 2008, p. 49).

É justamente nesse último aspecto que Marx se torna alvo também das críticas. E se essas críticas são enviesadas, de um lado, na medida em que os neoliberais norte-americanos não se dispõem a discutir diretamente com o autor de $O$ Capital, elas evidenciam, de outro, que o núcleo da diferença está centrado na compreensão do trabalho. Para os teóricos da Escola de Chicago, o trabalho envolveria, sobretudo, a força e o tempo, em troca dos quais o trabalhador recebe um salário. Se o trabalho aparece como abstração, seria fruto não da mecânica dos processos econômicos do capitalismo real, mas dos contornos que a teoria econômica adquiriu no interior da economia política clássica. Por isso, seria preciso realizar "uma crítica teórica da maneira como, no discurso econômico, o próprio trabalho apareceu como abstrato" (FOUCAULT, 2008, p. 305).

O deslocamento proposto pela análise neoliberal em relação aos objetos da economia política clássica é essencial para compreensão da mutação epistemológica que tem lugar no século XX, marcando distância significativa dos mecanismos clássicos de análise econômica, nos marcos da produção, da troca e do consumo em determinada estrutura social. É para as consequências das chamadas "opções substituíveis", segundo Foucault, que irá deslizar o foco da leitura neoliberal, quer dizer, para "a análise da maneira como são alocados recursos raros para fins que são concorrentes, isto é, para fins que são alternativos, que não podem se superpor uns aos outros" FOUCAULT, 2008, p. 306).

Distância marcada da interpretação baseada nos mecanismos internos do processo econômico, caberia, então, centrar a tarefa analítica em um comportamento humano e na "racionalidade interna desse comportamento humano" (FOUCAULT, 2008, p. 307). O desafio traçado pelos teóricos neoliberais é o de elucidar que tipo de cálculo se trata na atribuição, por parte dos indivíduos, de um fim específico e não outro, em cujo centro está a análise "da racionalidade interna, da programação estratégica da atividade dos indivíduos" (FOUCAULT, 2008, p. 307). 
É aí que a questão do trabalho - e, igualmente, da formação educativa - na esfera da análise econômica transforma-se, fundamentalmente, na questão de esclarecer "como quem trabalha utiliza os recursos de que dispõe", ou ainda, em uma mutação de perspectiva que privilegia o olhar de quem trabalha:

Será preciso estudar o trabalho como conduta econômica, como conduta econômica praticada, aplicada, racionalizada, calculada por quem trabalha. O que é trabalhar, para quem trabalha, e a que sistema de opção, a que sistema de racionalidade essa atividade de trabalho obedece? E, com isso, se poderá ver, a partir dessa grade que projeta sobre a atividade de trabalho um princípio de racionalidade estratégica, em que e como as diferenças qualitativas do trabalho podem ter um efeito de tipo econômico (FOUCAULT, 2008, p. 307).

Desse modo, o trabalhador torna-se um sujeito econômico ativo no campo da análise econômica, pois, para os neoliberais, seu trabalho é uma renda proveniente do investimento de um capital, que significará "tudo o que pode ser, de uma maneira ou de outra, uma fonte de renda futura" (FOUCAULT, 2008, p. 308). Portanto, o salário será entendido como a renda de um capital. Essa é a reflexão levada a cabo por dois economistas da Escola de Chicago: Theodore W. Schultz e Gary Becker, em cujos trabalhos Foucault se detém na aula de 14 de março de 1979, especialmente na interpretação acerca da teoria do capital humano.

Se na perspectiva neoliberal o salário é compreendido como renda de um capital, na esfera do trabalho a novidade dessa interpretação é ter definido o capital como "conjunto de todos os fatores físicos e psicológicos que tornam uma pessoa capaz de ganhar este ou aquele salário" (FOUCAULT, 2008, p. 308). Logo, o trabalho ganha outra dimensão, irredutível à definição como mercadoria ou ao aspecto temporal de utilização da força. O trabalho abrange a aptidão e a competência, do mesmo modo como o salário será fruto do investimento em um capital específico: o capital humano, que torna possível uma renda futura e que não se dissocia de seu portador.

O portador desse capital, o indivíduo-máquina, que é também trabalhador-empresa, é inseparável de suas competências físicas e psicológicas. E, na produção de fluxos de renda, ele mesmo, enquanto capital-competência, se compreende no interior de uma dinâmica repleta de variáveis, "de sorte que é o próprio trabalhador que aparece como uma espécie de empresa para si mesmo" (FOUCAULT, 2008, p. 310). Forma-empresa, portanto, de uma sociedade regida por uma ética social da empresa, que encontra seu lugar também nessa racionalidade de governo.

O capital humano aparece, então, como noção-chave das análises econômicas, desempenhando um papel central na analítica do neoliberalismo, com a ampliação do escopo dessas análises a esferas inexploradas. Segundo Schultz e Becker, o capital humano é composto por duas espécies de elementos, que constituem um conjunto de recursos raros para as competências-máquina que o dispõem: os inatos e os adquiridos. Ora, "como se produz e se acumula o chamado capital humano? De que ele se compõe? Quais 
são seus elementos inatos ou hereditários? Como ele pode ser adquirido por meio de políticas educacionais?" (FONSECA, 2013, p. 160).

Os elementos inatos irão se diferenciar dos adquiridos por serem, como indica a terminologia, da ordem do equipamento genético hereditário. Foucault mostra que, nos estudos dos neoliberais, a questão do capital genético adquire relevância - e isso, vale ressaltar, ainda na década de 1960 -, em termos que não serão aqueles tradicionais do racismo científico, mas que não deixam de marcar a entrada dos "bons equipamentos genéticos" em circuitos econômicos, na medida em que:

[...] as capacidades herdadas de uma população são semelhantes às propriedades originárias da terra no sentido de que são "dadas pela natureza" em qualquer período de tempo significativo para a análise econômica. As variações genéticas que poderiam afetar a distribuição e nível dessas capacidades acontecem tão vagarosamente que não têm relevância para a análise econômica. Da mesma forma parece ser verdadeiro que a distribuição das capacidades herdadas dentro de uma grande população mantém-se, aos efeitos práticos, constante ao longo do tempo, e que a distribuição dessas habilidades é aproximadamente a mesma seja o país pobre ou rico, atrasado ou moderno, sempre que a população seja numerosa (SHULTZ apud LÓPEZ-RUIZ, 2008, p. 129).

Com o desenvolvimento das pesquisas na área da engenharia genética e dos estudos biomoleculares, inaugurou-se a chamada "era da manipulação genética" e, com ela, uma série de problemas jurídicos e éticos, cujas implicações ainda são debatidas. Contudo, o que interessa aos neoliberais é que, em termos econômicos, a pesquisa genética possibilita "reconhecer os indivíduos de risco e o tipo de risco que os indivíduos correm ao longo de sua existência" (FOUCAULT, 2008, p. 313). Ou seja, a previsão de riscos e o estabelecimento de um quadro de diferenciação entre equipamentos genéticos mais ou menos "raros"; mais ou menos passíveis de serem afetados por determinadas doenças; mais ou menos produtivos, segundo seus traços genéticos.

Ademais, todo um cálculo estratégico de produção de filhos, com maior ou menor acúmulo de capital humano inato, será integrado ao campo das análises econômicas e sociais, pois será “em termos de constituição, de crescimento, de acumulação e de melhoria do capital humano que se coloca o problema político da utilização genética" (FOUCAULT, 2008, p. 314). Vale lembrar que, noutra ocasião, em conferência proferida na Universidade do Estado do Rio de Janeiro, em 1974, Foucault, ao tratar da biopolítica, já alertava para o fato de que, "na atualidade, com as técnicas de que a medicina dispõe, a possibilidade de modificar o equipamento genético das células não afeta somente o indivíduo ou sua descendência, mas toda a espécie humana. É todo o fenômeno da vida que entra no campo da intervenção médica" (FOUCAULT, 2001b, p. 47-48).

De outro lado, em relação aos elementos adquiridos na constituição do capital humano, o foco estará nos investimentos educacionais, compreendidos de forma expandida, para além da educação formal ou 
profissional, pois incluem, ainda, o tempo de afeto dedicado pelos pais aos filhos, os estímulos propostos às crianças, a proteção médica e o nível de cultura familiar - de uma cultura socialmente valorizada, convertida naquilo que Pierre Bourdieu chamou de capital cultural ao trabalhar os mecanismos de diferenciação reproduzidos pelo sistema escolar. Trata-se, enfim, de um conjunto de elementos relacionados ao entorno ambiental do indivíduo e aos investimentos que nele são feitos. Não à toa, segundo o sociólogo francês:

[...] a acumulação de capital cultural desde a mais tenra infância - pressuposto de uma apropriação rápida e sem esforço de todo tipo de capacidades úteis - só ocorre sem demora ou perda de tempo naquelas famílias possuidoras de um capital cultural tão sólido que fazem com que todo o período de socialização seja, ao mesmo tempo, acumulação. Por consequência, a transmissão do capital cultural é, sem dúvida, a mais dissimulada forma de transmissão hereditária de capital (BOURDIEU, 1997, p. 86).

Produzir capital humano demandaria, portanto, investimento em diversos níveis, além de uma formação permanente, pois, de acordo com os teóricos neoliberais, se há investimento no capital humano, há crescimento econômico, inovação na esfera produtiva e invenção que contribui para o desenvolvimento social e econômico dos países. Daí a centralidade dos investimentos no nível da formação educacional desde a infância, pois isso estaria na raiz da renda acrescida do capital humano, logo, da explicação de seu próprio desenvolvimento: "uma classe particular de capital humano, consistente do "capital configurado na criança', pode ser a chave de uma teoria econômica da população" (SCHULTZ, 1973, p. 9). Deste modo, os problemas econômicos dos países do Sul, por exemplo, não estariam, segundo os teóricos da Escola de Chicago, radicados na permanência das práticas coloniais ou no furor imperialista de que são alvos, mas "na insuficiência de investimento do capital humano" (FOUCAULT, 2008, p. 319), na medida em que baixo estoque de capital humano e estagnação econômica estariam em uma linha de continuidade ${ }^{v}$.

\section{(Des)governar}

Em um horizonte biopolítico e neoliberal, a vida humana adquire uma importância nuclear no interior das estratégias políticas que se dirigem a ela, às suas forças, à sua potencia, à sua forma plástica e genética, com vistas a elevar seu aporte valorativo e a governar suas condutas. Pois, na modernidade, a proteção à vida e o seu extermínio são as duas faces reversíveis da mesma moeda política, que espelham a economia das biopolíticas neoliberais. Por outro lado, há de se ressaltar o trabalho inventivo e incansável dos múltiplos movimentos de resistências, bem como as batalhas, em múltiplas frentes, contra o governo da individuação e das políticas identitárias normativas e planificadas. Resistências que visam à modificação 
dos regimes de saber, dos jogos de verdade, das relações de poder e de seus efeitos na administração da vida dos governados.

Se, como afirma Foucault, as principais lutas na atualidade se dão contra as formas de assujeitamento e contra o governo por individuação e totalização, como propor reconfigurações outras, que escapem das cristalizações em torno de estruturas unívocas e monolíticas de governo, que intentam restringir todo um campo aberto de possíveis a serem inventados? A reflexão levada a cabo por Foucault a partir dos anos 80 e a ênfase em uma relação criativa do sujeito consigo mesmo, talvez apontem alguns caminhos interessantes. Nesses trabalhos, Foucault investiga as relações entre o governo dos outros (formas políticas da governamentalidade) e o governo de si, bem como o cuidado de si e a subjetivação ética. E é deste modo que "o estudo das relações entre o governo dos outros e o governo de si, no marco da governamentalidade, permite, por outro lado, a articulação das estratégias de resistência" (CASTRO, 2009, p. 190-191).

Esse desdobramento ético de suas incursões responde também à reprimenda, não raro endereçada a Foucault, de que, ao fazer circular por toda a malha do tecido social, o poder aprisionava os sujeitos e impediria qualquer forma de resistência ou linha de fuga, no claustro de modalidades de governo, simultaneamente, individualizantes e totalizantes. Foucault, entretanto, ressaltaria que:

Eu quero dizer que as relações de poder suscitam necessariamente, reclamam a todo instante, abrem a possibilidade de uma resistência; e é porque há possibilidade de resistência, e resistência real, que o poder daquele que domina trata de manter-se com tanto mais força, tanto mais de astúcia quanto maior a resistência. De modo que é mais a luta perpétua e multiforme o que eu trato de fazer aparecer do que a dominação morna e estável de um aparato uniformizante. Em toda parte se está em luta (FOUCAULT, 2001, p. 407).

O que está sublinhado, assim, é que a resistência não é o outro do poder, que viria de fora, mas elemento fundamental das relações de poder. Nessa perspectiva, não se trata de tipificar o poder na ordem jurídica da legitimidade e da ilegitimidade ou na ordem da moralidade, mas de considerá-lo a partir de suas condições de existência reais e das práticas sociais efetivas. Essas práticas de liberdade, por sua vez, são indissociáveis da forma que se dá à subjetividade e à abertura do campo para que se instaurem novas relações de poder. Não é fortuito que Foucault chame atenção, em $O$ Sujeito e o Poder, para a luta contra as formas de sujeição, que vinculam o sujeito a si mesmo por meio de uma identidade naturalizada e, desse modo, asseguram sua sujeição aos outros. Foucault irá nomear essas lutas de "batalhas contra o governo da individuação" (FOUCAULT, 2001d, p. 1046).

A crise de governamentalidade de que nos fala Foucault, além disso, dá a ver o esgarçamento de certas práticas de subjetivação que são colocadas em xeque por lutas transversais, imediatas e específicas, que se dão em nome da promoção de novas formas de sociabilidade e de autoconstituição, para além 


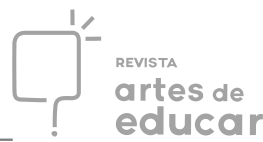

daquelas moldadas por critérios econômicos. E, especificamente, no que tange à governamentalidade neoliberal, trata-se da própria concepção de liberdade em questão, encarada como problema geopolítico, ético, social e filosófico de nosso tempo. É, pois, no nexo entre crise de governamento - isto é, no colapso na condução de condutas dos sujeitos em direção a determinados fins - e lutas contra o governo da individuação que as resistências tensionam as premissas de práticas políticas que incidem diretamente sobre as subjetividades, na medida em que “onde há poder, há resistência” (FOUCAULT, 2009, p. 105).

Deste modo, a capacidade de intervenção e ação sobre os processos de subjetivação é fundamental como possível linha de fuga dos governos intoleráveis sobre a vida humana e da concepção dos sujeitos como empresas a serem investidas, ativadas e geridas segundo a lógica da competitividade e do autoinvestimento produtivo.

\section{Considerações finais}

À ocasião da morte de Foucault, em 1984, o mundo passava por transformações radicais em regimes políticos, instituições e práticas de governo, que se reorganizavam sob a pressão das crises geopolíticas e econômicas e de um modo de governamentalidade que se disseminou pelos quatro cantos do mundo como discurso e modalidade de exercício do poder verdadeiros.

Em um cenário no qual os mercados adquirem centralidade enquanto estrutura primordial de sustentação, equiparação e fundamentação de uma racionalidade governamental, é patente a redução da política aos planos e às operações econômicas, forjadas por economistas "inclinados a confundir as coisas da lógica com a lógica das coisas”, como sublinhava Bourdieu (1998, p. 2-3) nos últimos anos do século passado. Mercado global que traz as marcas da instabilidade sistêmica e da insegurança endêmica, considerando os sujeitos, acima de tudo, como meros operadores econômicos, investidores, acionistas, managers.

Atravessados pela intensificação da gestão participativa, que assume menos a forma de uma concessão do que de injunção, induzido pelo ideário de bem-estar e segurança de todos, novas práticas de controle das subjetividades e de normalização se instauram, associadas à dinâmica dos riscos, da produção de corpos elimináveis e da insegurança permanente, que movem as engrenagens da in/exclusão das sociedades de controle.

De modo surpreendente, temos assistido nos últimos decênios à escalada do discurso neoliberal no campo da educação, que tensiona currículos e percursos formativos, inserindo nas instituições de ensino valores, práticas e sentidos de uma cultura do empreendedorismo e das competências. Como visão de mundo, essa cultura adquire os contornos normativos de uma direção que individualiza os microempresários, enquanto os torna incapazes de "se agenciarem entre si em torno da invenção de novos 
modos de vida, e de intervenção em favor de novos modos de existencialização e de sensibilidade, que não aqueles apregoados pelo mercado" (COSTA, 2009, p. 12).

Devido às distintas perspectivas acerca da dinâmica das relações de poder nas sociedades neoliberais, nutrem-se também diferentes compreensões da própria compleição e composição das resistências ao poder, seu estatuto e suas estratégias. Se as críticas à governamentalidade neoliberal continuam a ressoar e a provocar uma série de debates calorosos, deve-se à atualidade da questão e de um exercício crítico que ressalta, sobretudo, a importância de "dizer como funciona um certo regime, em que ele consiste e de impedir toda uma série de manipulações e de mistificações" (FOUCAULT, 2001c, p. 911).

Penso que esse exercício faz coincidir o trabalho de diagnóstico do presente e da intervenção na atualidade, imprescindíveis para problematizarmos temas e campos que se abrem à interferência e à aderência de outras práticas e corpos discursivos. Além disso, essa maneira de se relacionar com o presente histórico seria indissociável, nas trilhas de Foucault, de um ethos filosófico que envolve a crítica permanente de nosso tempo e de nós mesmos. Ontologia crítica, pois, que retraça os nexos entre sujeito, veridição e atualidade, "como uma atitude, um ethos, uma vida filosófica na qual a crítica disto que nós somos é, ao mesmo tempo, análise histórica dos limites que nos são postos e experimentados na sua ultrapassagem possível” (FOUCAULT, 2001e, p. 1396).

Na tentativa de compreender algumas dinâmicas e processos inerentes à governamentalidade neoliberal, aqui são esboçadas algumas contribuições ao debate, com desdobramentos evidentes no campo da educação, entendida como prática social de formação humana, e do pensamento contemporâneo. Contribuições que podem ser pensadas como desafios que nos são colocados diante da situação atual, na qual o canto da sereia do neoliberalismo não cessa de investir as práticas educativas. Mas a educação, é bem verdade, "pode ser também elemento gerador de novas formas de concepções de mundo capazes de se contraporem à concepção de mundo dominante em determinado contexto sociocultural" (SEVERINO, 1986, p. 96). É aí, talvez, que a própria filosofia pode encontrar sua força crítico-reflexiva potencializada, no exercício permanente que "busca relançar tão longe e tão amplamente quanto possível o trabalho infinito da liberdade" (FOUCAULT, 2001e, p. 1393).

\section{Referências}

AUDARD, Catherine. Qu'est-ce que le libéralisme? Éthique, politique, société. Paris: Gallimard, 2009. BAZZICALUPO, Laura. Produção de segurança e incerteza dos critérios. In: AVELINO, Nildo; VACCARO, Salvo (Org.). Governamentalidade | Segurança. São Paulo: Intermeios, 2014.

BECK, Ulrich. Sociedade de risco. Trad. Sebastião Nascimento. 2a . Ed. São Paulo: Ed. 34, 2011. 
BOURDIEU, Pierre. Capital cultural, escuela y espacio social. México: Siglo Veinteuno, 1997.

BOURDIEU, Pierre. L'essence du néolibéralisme. Le Monde Diplomatique, Paris, mar. 1998. Disponível em: www.monde-diplomatique.fr/1998/03/BOURDIEU/10167\#nh1 Acesso em: 15 abr. 2020.

BROWN, Wendy. Cidadania sacrificial, neoliberalismo, capital humano e políticas de austeridade. Trad. Juliane Bianchi Leão. Rio de Janeiro: Zazie Edições, 2018.

CASTRO, Edgardo. Vocabulário de Foucault: um percurso pelos seus temas, conceitos e autores. Trad. Ingrid Müller Xavier. Belo Horizonte: Autêntica Editora, 2009.

COSTA, Sylvio de Sousa Gadelha. Governamentalidade neoliberal, teoria do capital humano e empreendedorismo. Educação \& Realidade, 34 (2), p. 171-186, mai./ago. 2009.

DARDOT, Pierre; LAVAL, Christian. La nouvelle raison du monde: essai sur la société néolibérale. Paris: Éditions La Découverte, 2009.

DELEUZE, Gilles. Post-Scriptum sobre as sociedades de controle. In: Conversações. São Paulo: Editora 34, 2013.

DELORS, Jacques. Educação: um tesouro a descobrir. Relatório para a UNESCO da Comissão Internacional sobre a Educação para o Século XXI. Trad. José Carlos Eufrázio. São Paulo: Cortez, 2001.

DUARTE, André de Macedo. Vidas em risco: crítica do presente em Heidegger, Arendt e Foucault. Rio de Janeiro: Forense Universitária, 2010.

FONSECA, Márcio Alves da. Para pensar o público e o privado: Foucault e o tema das artes de governar. In: RAGO, Margareth; VEIGA-NETO, Alfredo (Org.). Figuras de Foucault. $3^{\mathrm{a}}$. Ed. Belo Horizonte: Autêntica Editora, 2013.

FOUCAULT, Michel. “À propos de la généalogie de l'éthique: un apeçu du travail em cours”. In: Dits et Écrits. II. Paris: Gallimard, 2001. p. 1428-1450.

FOUCAULT, Michel. "Crise de la médicine ou crise de la antimédicine". In: Dits et Écrits. II. Paris: Gallimard, 2001b. p. 40-58.

FOUCAULT, Michel. "Entretien avec Michel Foucault". In: . Dits et Écrits. II. Paris: Gallimard, 2001c.

FOUCAULT, Michel. História da sexualidade I: A vontade de saber. Trad. Maria Thereza da Costa Albuquerque e J. A. Guilhon Albuquerque. Rio de Janeiro: Edições Graal, 2009.

FOUCAULT, Michel. "Le sujet et le pouvoir". In: . Dits et Écrits. II. Paris: Gallimard, 2001d. p. 10411062.

FOUCAULT, Michel. Nascimento da biopolítica. Trad. Eduardo Brandão. São Paulo: Martins Fontes, 2008.

FOUCAULT, Michel. “Qu'est-ce que les lumières? (1984)”. In: 2001e. p. 1381-1397.

Dits et Écrits. II. Paris: Gallimard,

FOUCAULT, Michel. Sécurité, territoire, population: cours au Collège de France, 1977-1978. Paris, Gallimard/Seuil, 2004.

GENTILI, Pablo. Neoliberalismo e educação: manual do usuário. In: ; SILVA, Tomaz Tadeu da (Org.). Escola S. A.: quem ganha e quem perde no mercado educacional no neoliberalismo. Brasília: CNTE, 1996.

HAMANN, Trent H. Neoliberalismo, governamentalidade e ética. Revista Ecopolítica, n. 3, p. 99-133, mai./ago. 2012. Disponível em: http://revistas.pucsp.br/index.php/ecopolitica/issue/view/755/showToc Acesso em: 15 abr. 2020. 
LAZZARATO, Maurizio. Biopolítica/Bioeconomia. In: PASSOS, Isabel Christina Friche (Org.). Poder, normalização e violência: incursões foucaultianas para a atualidade. Belo Horizonte: Autêntica Editora, 2008.

LÓPEZ-RUIZ, Osvaldo. A técnica como capital e o capital humano genético. Revista Novos Estudos Cebrap, n. 80, mar. 2008, p. 127-139. Disponível em: http://www.scielo.br/pdf/nec/n80/a09n80.pdf Acesso em: 10 abr. 2020.

LÓPEZ-RUIZ, Osvaldo. Os executivos das transnacionais e o espírito do capitalismo: capital humano e empreendedorismo como valores sociais. Rio de Janeiro: Azougue Editorial, 2007.

RAMOS DO Ó, Jorge. Notas sobre Foucault e a governamentalidade. In: FALCÃO, Lucas Felipe; SOUZA, Pedro de (Org.). Michel Foucault: perspectivas. Florianópolis: Clicdata Multimídia/Achiamé, 2005.

REIS, Diego dos Santos. Michel Foucault, a gestão dos ilegalismos e a razão criminológica neoliberal. Revista de Filosofia Aurora, Curitiba, v. 32, n. 55, p. 279-299, jan./abr. 2020.

REIS, Diego dos Santos. O governo da emergência: Estado de exceção, guerra ao terror e colonialidade. Rio de Janeiro: Multifoco, 2020b.

STANCHI, Malu; REIS, Diego dos Santos. Criminalização e superencarceramento do corpo negro: sistema de promoção do necropoder nos centros de detenção brasileiros. Revista do Observatório de Direitos Humanos, Brasília, v. 5, n. 5, p. 4-17, jul./dez., 2018.

SEVERINO, Antônio Joaquim. Educação, ideologia e contra-ideologia. São Paulo, EPU, 1986.

SCHULTZ, Theodore. Capital humano: investimentos em educação e pesquisa. Rio de Janeiro: Zahar Editores, 1973.

WACQUANT, Loïc. Foucault, Bourdieu et l'État pénal à l'ère néolibérale. In: ZAMORA, Daniel (Org.). Critiquer Foucault: Les années 1980 et la tentation néolibérale. Bruxelles: Ed. Aden, 2014.

Recebido em: 29/04/2020.

Aceito em: 22/07/2020.

Notas

\footnotetext{
${ }^{\text {i }}$ Pós-doutorando na Faculdade de Educação da Universidade de São Paulo (FEUSP). Doutor em Filosofia pela Universidade Federal do Rio de Janeiro (UFRJ). Professor Substituto de Filosofia da Educação da Faculdade de Educação da UFRJ. Professor Colaborador da FEUSP. E-mail: diegoreis.br@ gmail.com Rio de Janeiro/RJ; ORCID: https://orcid.org/0000-0001-6977-7166

ii Lazzarato propõe a figura do "homem endividado" como aquela que está no cerne dos controles das subjetividades hoje, ancorada na relação débito/crédito e na 'dívida como fundamento do social'. Cf. LAZZARATO, Maurizio. La Fabrique de l’homme endetté: essai sur la condition néolibérale. Paris: Éditions Amsterdam, 2011.

iii As traduções do livro de Catherine Audard são minhas.

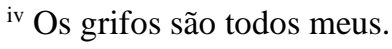

${ }^{v}$ Em 2002, por exemplo, o Projeto Regional de Educação Para a América Latina e o Caribe (PREALC), realizado no âmbito da Organização das Nações Unidas para a Educação, a Ciência e a Cultura (UNESCO), anunciou a inclusão do empreendedorismo
} 
como um dos pilares fundamentais para a educação, no bojo do chamado Relatório Delors, de 1996. Cabe sublinhar que esse relatório, intitulado "Educação: um tesouro a descobrir", aponta para a necessidade do "estabelecimento de novas relações entre política educacional e política de desenvolvimento, a fim de fortalecer as bases do saber e dos savoir-faire nos países em tela: incentivo à iniciativa, ao trabalho em equipe, às sinergias realistas, a partir dos recursos locais, assim como ao trabalho por conta própria e ao empreendedorismo (DELORS, 2001 [1996], p. 29]). O PREALC, ao tomar como guia o Relatório Delors, destaca o empreendedorismo como um dos quatro focos estratégicos a serem priorizados nas práticas educativas, ao lado do "aprender a ser, a conhecer, a fazer e a viver juntos". 